\title{
Acknowledgements and a note on the text
}

No single book can cover Freud's 7000 pages of writing on psychoanalysis, plus his letters, let alone the bodies of work of those associated with him, or his adversaries. So the book has to be selective. Though Freud is sometimes hard, and Lacan obviously so, reading systematically through the book, rather than just dipping, will make the ideas emerge comparatively straightforwardly. I use the Standard Edition of Freud (called SE), translated principally by James Strachey. There are many problems about his translations (see Ornston, 1992, and Laplanche, 1992), but the solid advantage of the $S E$ is its footnoting and referencing. I have given plentiful crossreferences, to follow ideas through. Given the cramped space, I ask readers to make extensive use of the book's index to check explanations and definitions, and to follow reading suggestions via the Bibliography.

Thanks to all those who have discussed this subject with me over many years: to Bob Pattison for many conversations, especially on Klein, to Howard Booth for comments on the Klein chapter, to Ben Moore and James Smith who both read substantial sections, and to Will Simpson who read the sections on Lacan, and Mark Gardner who read the early sections. Thanks to Jack Sullivan and Jack Wittels for help with the manscript. This book is for Pauline, Kirsten, and Felix, with love. 